\title{
UYANIK FİBEROPTIKK ENTÜBASYON: BEKLENEN ZOR HAVA YOLU
}

\author{
Awake Fiberoptic Intubation: Anticipated Difficult Airway
}

\section{Gülçin AYDIN", Ayşe Gizem SARAÇOĞLU², Ahmet Tuğrul ŞAHİN, Murat ALPARSLAN ${ }^{4}$, Seydi GÜNDOĞAN ${ }^{5}$, Yahya Fatih KOÇAK ${ }^{6}$, Ela CÖMERT ${ }^{7}$}

\author{
1,2,3,4,5,6 Kırıkkale Üniversitesi Tip Fakültesi, Anesteziyoloji ve Reanimasyon A.D., KIRIKKALE, TÜRKIYYE \\ ${ }^{7}$ Kırıkkale Üniversitesi Tıp Fakültesi, Kulak Burun Boğaz A.D., KIRIKKALE, TÜRKIYYE
}

ÖZ

ABSTRACT

Zor hava yolu anestezistler tarafından zor yüz maske ventilasyonu ve zor trakeal entübasyonu kapsayan bir durum olarak tanımlanır. Entübasyon girişimlerinin \%0.5-2.5'inde zorlukla karşılaşılır. Başarısız girişimler perioperatif dönemde morbidite ve mortaliteyi etkilemektedir. Beklenen zor hava yolu vakalarında ayrıntılı bir preoperatif değerlendirme ve ekipman hazırlığı önemlidir. Zor hava yolunu öngörebilecek çeşitli anatomik ve antropometrik özellikler saptanan hastalarda yaygın fiberoptik entübasyon ihtiyacı olmaktadır. Fiberoptik entübasyon için ideal sedasyon tekniği sağlanmalıdır. Bu teknik hastanın anksiyetesini azaltan, konforunu bozmayan ve hemodinamik stabilitesini bozmayan bir teknik olmalıdır. İşlem süresinde hastaların uyumlu ve koopere olması da çok önemlidir. Biz bu yazımızda beklenen zor hava yolu vakasındaki anestezi yaklaşımımızı literatürler eşliğinde sunmayı amaçladık.

Anahtar Kelimeler: Uyanık fiberoptik entübasyon, zor havayolu
Difficult airway is defined as a situation which involves difficult face mask, ventilation and difficult endotracheal intubation by anesthesiologists. The incidence of difficult intubation is 0.5 $2.5 \%$. Unsuccessful attempts effects the perioperative morbidity and mortality. A detailed preoperative evaluation and equipment preparation is important in anticipated difficult airway cases. In the patients which have anatomical and anthropometric features which leads to difficult airway, it's often to need fiberoptic intubation. It should be considered to provide the ideal sedation technique for fiberoptic intubation. This technique should decrease the patient's anxiety and preserve the comfort and the hemodynamic stability. The patient's compatibility and cooperation is also important during the procedure. Our goal in this report is to represent the anesthesic approach in anticipated difficult airway with literatures.

Keywords: Awake fiberoptic intubation, difficult airway 


\section{GíRIŞ}

Zor hava yolu anestezistler için hala en büyük zorluklardan biri olarak kabul edilir. Başarısız entübasyon ve hastayı ventile edememe nadir fakat hayatı tehdit eden dramatik sonuçları açısından oldukça önemlidir (1). Zor hava yolunun yönetimi için anestezi öncesi ayrıntılı değerlendirme, operasyon için iyi bir planlama- ön hazırlık ve hasta ile iletişim çok önemlidir (2). Beklenen zor hava yolu vakalarında; hasta uyanık olmalı ve spontan ventilasyon korunacak şekilde hava yolu güvence altına alınmalıdır. Fiberoptik entübasyon böyle durumlarda standart bir yaklaşım şeklidir (3). Biz bu yazımızda beklenen zor hava yolu vakasında anestezi yaklaşımımızı literatürler eşliğinde sunmayı amaçladık.

\section{OLGU}

Kulak Burun Boğaz bölümü tarafindan derin boyun absesi nedeni ile acil operasyonu planlanan 30 yaşında, vücut kitle indeksi (VKİ) 31.1 olan kadın hastanın preoperatif değerlendirmesinde 10 paket/yıl sigara öyküsü vard1. Laboratuar değerleri normal idi. Hastanın hava yolu muayenesinde ağız açıklığının dar olduğu $(<2 \mathrm{~cm})$ için mallampati skoru değerlendirilemedi. Să̆ yanaktan başlayıp çene altından bilateral şekilde boyun bölgesine uzanan şişlik ve kızarıklık vardı (Resim 1).

Amerikan Anesteziyoloji Derneği (ASA) risk sınıflamasına göre ASA IE olarak değerlendirildi. Olası zor havayolu yönetimi için (çeşitli boylarda oral, nazal airwayler ve endotrakeal tüpler (ETT), klavuz teller, magill ve macintosh bleydler, laringeal mask airwaylar (LMA), perkütan trakeostomi seti ve fiberoptik bronkoskop) gerekli hazırlıklar yapıldı. Hastaya fiberoptik ile uyanık entübasyon planlandı. Hasta yapılacak işlem konusunda bilgilendirildi ve yazılı onam imzalatıldı. Operasyon odasına gelen hastaya elektrokardiyografi (EKG), sistolik arter basınc1 (SAB), diastolik arter basıncı (DAB), ortalama arter basınçları (OAB), kalp tepe atımları (KTA), oksijen satürasyon (SPO2) değerleri ile standart monitörizasyon uygulandı.

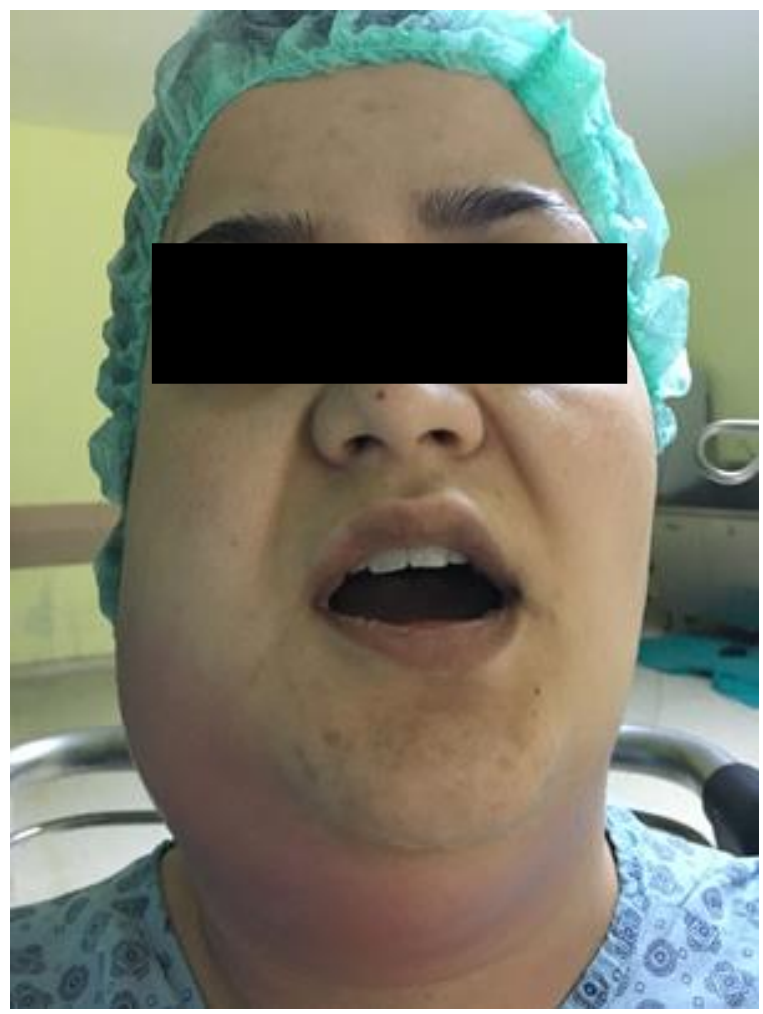

Resim 1: Ağız açıklığının darlığg $(<2 \mathrm{~cm})$ ve sağ yanaktan başlayıp çene altından bilateral şekilde boyun bölgesine uzanan şişlik ve kızarıklık

Hastanın ilk değerleri TA:100/61 mmHg, Nabız:110/dk, SpO2: \%99 olarak kaydedildi. Hasta oturur pozisyona alındıktan sonra dil kökü ve farinkse Lidokain $\mathrm{HCl}$ sprey (Vemcaine ${ }^{\circledR}$ pump sprey \%10 Vem İlaç Sanayi ve Ticaret Ltd. Şti. Türkiye) ile lokal anestezi uygulandı. Nazal $\mathrm{O}_{2}$ ile $4 \mathrm{~L} / \mathrm{dk}^{\prime}$ dan oksijenasyon sağland. Takiben 0.03-0.05 mg/kg intravenöz (iv) midazolam (Dormicum ${ }^{\circledR}$, Roche) ve 1 $\mathrm{mcg} / \mathrm{kg}$ iv fentanil (Fentanyl ${ }^{\circledR}$, Janssen, Janssen Pharmaceutica) ile sedasyon sağlandi. Fiberoptik bronkoskop ile girilerek orofarenks değerlendirildi. Hasta başına uygun pozisyon verildikten sonra vokal kordlar görüldü (Resim 2 A-B-C), fiberoptik ile rima glottisten geçildi (Resim 3). Spontan solunumu olan hasta işlem boyunca hiç desatüre olmadı ve 
hemodinamik stabilite hiç bozulmadı. Bu esnada hastaya $2 \mathrm{mg} / \mathrm{kg}$ propofol iv (Propofol ${ }^{\circledR} \% 1$, Fresenius), $1 \mathrm{mg} / \mathrm{kg}$ rokuronyum bromür iv (Esmeron ${ }^{\circledR}$, Organon) yapıld1. 7.5 spiralli endotrakeal tüp bronkoskobun üzerinden kaydırılarak entübe edildi (Resim 4). Akciğerlerin steteskop ile bilateral eşit olarak havalandığı ve entidal karbondioksitin trasesi görülerek tüpün yeri doğrulandı. Anestezi idamesi $\% 2$ Sevofluran ve $\% 50 \quad \mathrm{O}_{2} / \% 50$ hava ile sağlandı. Bir saat onbeş dakika süren vakanın nöromuskuler bloğu $4 \mathrm{mg} / \mathrm{kg}$ iv suggammadeks (Bridion ${ }^{\circledR} 200 \mathrm{mg} / 2 \mathrm{ml}$ Schering Plough Trbbi Ürünler Ticaret A.Ş.) ile sağlanarak sorunsuz şekilde ekstübe edildi. Postoperatif derlenme odasında $15 \mathrm{dk}$ kalan hasta servise gönderildi.

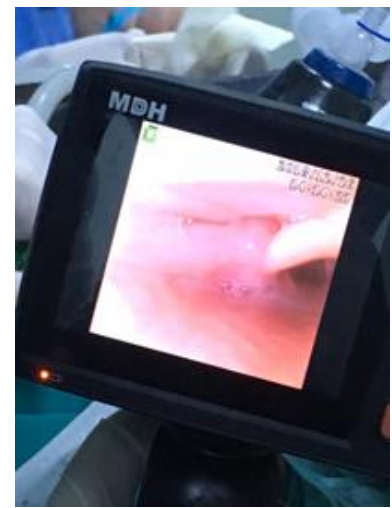

A

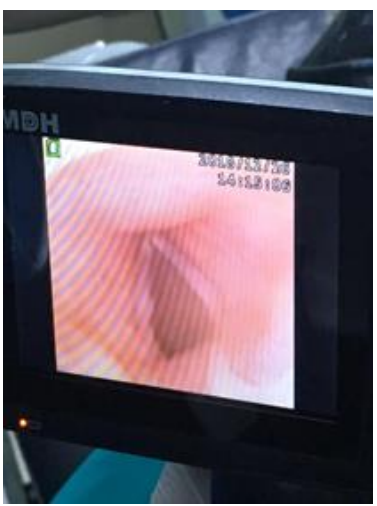

B

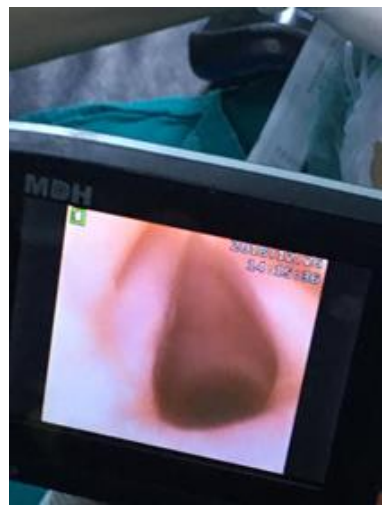

C

Resim 2: Fiberoptik bronkoskop ile vokal kordların görülmesi (A-B-C)

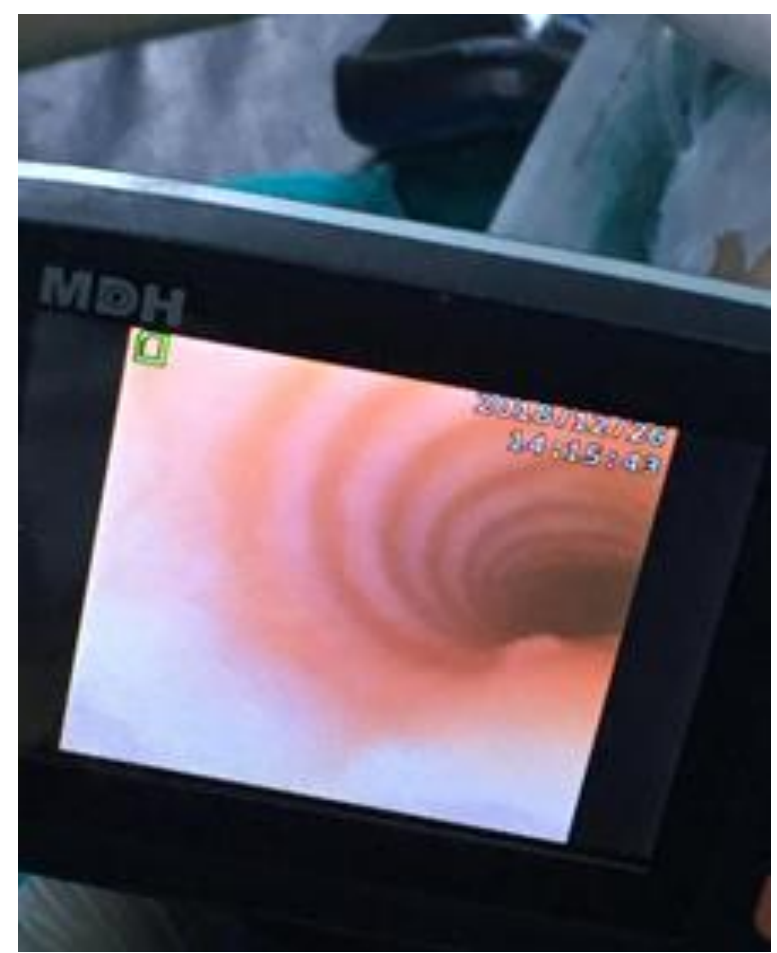

Resim 3: Fiberoptik ile rima glottisten geçilmesi

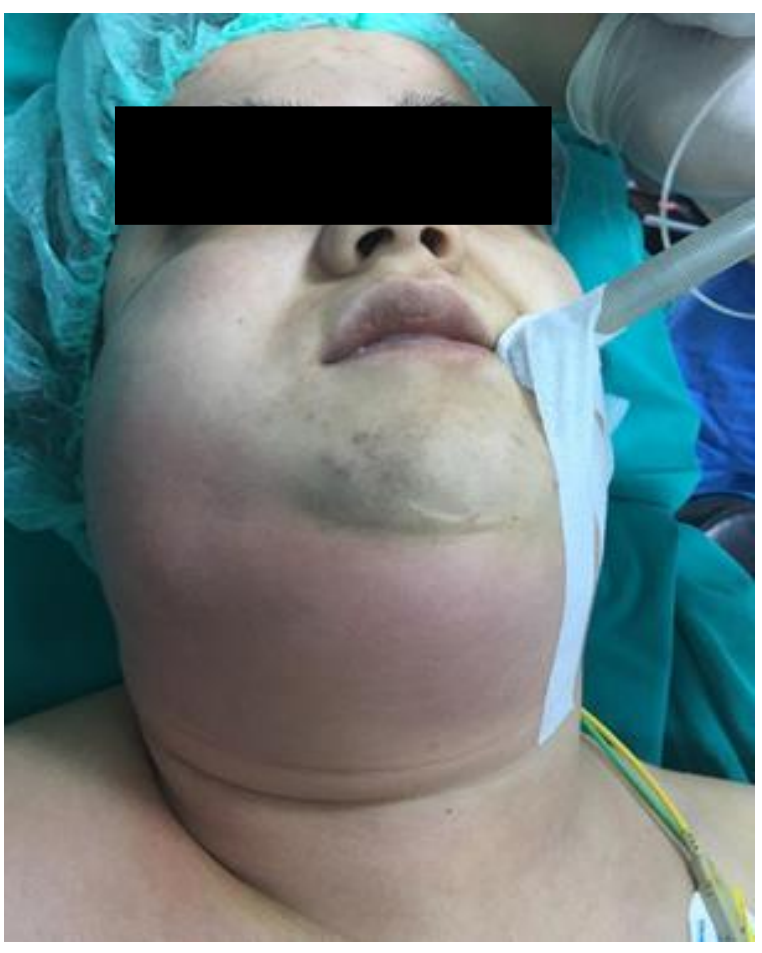

Resim 4: Entübasyon sonrası 


\section{TARTIŞMA}

Zor entübasyonla karşılaşıldığında; oral veya nazal fiberoptik bronkoskop (FOB) ile entübasyon, kör oral veya nazal entübasyon, entübasyon laringeal maske (ILMA, Fastrach ${ }^{\circledR}$ ), laringeal maske (LMA) gibi farklı yaklaşımlar veya bunların birlikte kullanımı yoluna gidilebilir. Ancak hiçbir yöntemin tüm koşullarda iyi sonuç vermeyeceği unutulmamalıdır (4). Fiberoptik entübasyon (FOE) ise hem öngörülen hem de beklenmeyen zor havayolu yönetiminde önemli bir tekniktir. Zor entübasyon ve zor laringoskopiyi öngörebilecek çeşitli anatomik ve antropometrik özellikler saptanan hastalarda yaygın FOE ihtiyacı olmaktadır. $\mathrm{Bu}$ durumlar; ağız açıklığının kısıtlı olması, sınırlı tiromental mesafe, enfeksiyon, temporomandibular eklem problemleri ve obezite olarak sayılabilir. Bu tür hastalarda uyanık entübasyon; maske ventilasyonu ve aspirasyon riski açısından gerekmektedir $(5,6)$. Nitekim bizim hastamızın VKİ'nin yüksek olması, ağız açıklığının kısıtlılığ1 ve boyun bölgesindeki abse zor hava yolu kriterlerini karşıllyordu. $\mathrm{Bu}$ anatomik özellikler ve abse poşunun ağız içine açılması sonrası aspirasyon riskinden dolayı uyanık entübasyonu düşünmemizi ve fiberoptiği tercih etmemize neden oldu.

FOE için ideal sedasyon tekniği sağlanmalıdır. Bu durum; hastaların spontan solunumunun korunduğu, koopere-uyumlu olduğu ve fiberoptiğin geçişine tolerans göstermesi ile mümkündür. Bu teknik aynı zamanda hastanın anksiyetesini azaltan, konforunu bozmayan ve hemodinamik stabilitesini bozmayan bir teknik olmalıdır (6). Uyanık entübasyonda laringospazm ve öksürük, entübasyona yanıt olarak sıklıkla karşılaşılır. Ağrılı bir işlem olması sebebiyle de etkili bir topikal hava yolu anestezisi zorunludur. Ayrıca yüksek dozda kullanılan midazolam ile anksiyolitik ve sedatif etki sağlanırken fentanil gibi opioidlerle potansiyel analjezik etki sağlanmış olur ve bu sayede hemodinamik değişiklikler ve öksürük önlenerek başarılın bir havayolu enstrümentasyonu sağlanabilir (6). Zor hava yolu öngördüğümüz hastamızda midazolam-fentanil kombinasyonu ile iyi bir sedasyon ve analjezik etki sağlandı. Topikal hava yolu anestezisi ile öksürük-laringospazm gibi yanıtlar olmad1. Entübasyon yapılana kadar spontan solunum ve hemodinamik stabilite korundu. Sorunsuz bir şekilde hava yolu enstrümentasyonu sağlandı.

Zor hava yolu öngörülen hastalarda iyi bir preoperatif değerlendirme ile beraber, zor hava yolu ekipmanlarının planlama ve hazırlığı oldukça önemlidir. Hastaya işlemin anlatılması hastanın kooperasyon ve uyumunu artırmakla beraber işlemin başarı şansını arttırmaktadır. Zor entübasyon ve zor laringoskopi durumlarında birçok yöntem olmakla beraber FOE kullanımı da mutlaka akılda tutulmalidir.

\section{KAYNAKLAR}

1. Popovici SE, Mitre C. Difficult airway management- a constant challenge. Rom J Anaesth Intensive Care. 2018;25(2):93-4.

2. Law JA, Morris IR, Brousseau PA, de la Ronde S, Milne AD. The incidence, success rate, and complications of awake tracheal intubation in 1,554 patients over 12 years: an historical cohort study. Can J Anaesth. 2015;62(7):736-44.

3. Schäuble JC, Heidegger T. Erratum to: Management of the difficult airway: Overview of the current guidelines. Anaesthesist. 2019;68(1):29.

4. Uzun Ş, Şahin A, Köse EA, Aypar Ü. Beklenmeyen zor entübasyonla karşılaşılan bir olguda larengeal mask airway yoluyla fiberoptik entübasyon. Türkiye Klinikleri J Anest Reanim. 2008;6(1):28-32.

5. Collins SR, Blank RS. Fiberoptic intubation: an overview and update. Respir Care. 2014;59(6):865-78.

6. Tsukamoto M, Hitosugi T, Yokoyama T. Awake fiberoptic nasotracheal intubation for patients with difficult airway. J Dent Anesth Pain Med. 2018;18(5):301-4. 